\title{
Bisphosphonates regulate cell proliferation, apoptosis and pro-osteoclastic expression in MG-63 human osteosarcoma cells
}

\author{
JUN CHANG, WEI WANG, HUI ZHANG, YONG HU and ZONGSHENG YIN \\ Department of Orthopaedics, First Affiliated Hospital, Anhui Medical University, Hefei, Anhui 230022, P.R. China
}

Received February 16, 2012; Accepted May 9, 2012

DOI: $10.3892 / 01.2012 .723$

\begin{abstract}
Bisphosphonates are well established in the management of cancer-induced skeletal complications. Recent studies suggest that nitrogen-containing bisphosphonates (N-BPs) promote the apoptosis of cancer cells as well as osteoclasts in bone metastatic sites. To investigate whether N-BPs exhibit a direct antitumor effect on osteoclasts, the current study investigated the effects of zoledronic acid (ZOL) on MG-63 cells in vitro. MG-63 cells were treated with ZOL. The inhibitory effect of ZOL on the growth of MG-63 cells was measured by MTT assay. ZOL-induced apoptosis of the MG-63 cells was examined by Hoechst 33258 staining, electron microscopy, Annexin V-FITC and propidium iodide staining. Reversetranscription polymerase chain reaction (RT-PCR) and western blotting analysis were employed to assess the expression of osteoprotegerin (OPG) and receptor activator of nuclear factor- $\kappa \mathrm{B}$ ligand (RANKL). The MTT assay showed that ZOL induced a distinct dose- and time-dependent reduction of cell viability with an $\mathrm{IC}_{50}$ value of $52.37 \pm 1.0 \mu \mathrm{M}$ for $72 \mathrm{~h}$. Flow cytometric analysis further revealed that the cell apoptosis was induced by arrest of the cell cycle in the $\mathrm{G}_{1}$ phase. RT-PCR and western blot analysis demonstrated that ZOL upregulated OPG expression. These results suggest that ZOL has direct effects on osteosarcoma cell growth and apoptosis. Increased OPG expression is an indirect effect, possibly via changes in the local microenvironment.
\end{abstract}

\section{Introduction}

Osteosarcoma is the most common primary malignant bone neoplasm with poor prognosis in children and young adolescents. In the past 27 years, the rate of disease-free survival

Correspondence to: Professor Zongsheng Yin, Department of Orthopaedics, First Affiliated Hospital, Anhui Medical University, Hefei, Anhui 230022, P.R. China

E-mail: yinzongsheng@sina.com.cn

Key words: bisphosphonates, osteosarcoma, osteoprotegerin, receptor activator of nuclear factor- $\kappa \mathrm{B}$ ligand appeared to be stable (62 and 66\% for patients treated in two respective periods 1986-1989 and 1997-1999 in our studies), despite the use of intensive neoadjuvant chemotherapy and radiation therapy (1). Thus, novel agents need to be developed to establish an effective therapeutic strategy against osteosarcoma.

Bisphosphonates are analogs of endogenous pyrophosphate that strongly bind to hydroxyapatite on the bone surface. Nitrogen-containing bisphosphonates (N-BPs) inhibit the activity of farnesyl diphosphate (FPP) synthase, a key enzyme in the mevalonate pathway, and thereby reduce the prenylation of proteins that are essential for normal cell function and survival $(2,3)$. N-BPs may have direct cytostatic and anti-proliferative effects against a variety of tumor cells, including myeloma, breast, prostate and pancreatic cancers, in a concentration- and time-dependent manner (4-7).

Previously, it was reported that N-BPs may also exhibit direct effects on osteoblast cells by altering the expression of receptor activator of nuclear factor- $\kappa \mathrm{B}$ ligand (RANKL) and osteoprotegerin (OPG) (10). OPG is a soluble decoy receptor for RANKL that blocks osteoclast formation by inhibiting the binding of RANKL to the receptor activator of nuclear factor- $\kappa \mathrm{B}$ (RANK) $(8,9)$. The OPG/RANK/RANKL system was demonstrated to be abnormally regulated in several malignant osteolytic pathologies such as osteosarcoma (10). By contrast, production of its endogenous counteracting decoy receptor OPG is either inhibited or too low to compensate for the increase in RANKL production. Thus, the OPG/ RANK/RANKL system is essential for understanding of the pathophysiology of the bone microenvironment and offers pharmacological targets for new antitumor drugs $(11,12)$.

Preclinical data have indicated that N-BPs accumulated in bone are able to either directly or indirectly inhibit osteoclastic resorption and alter the bone microenvironment $(13,14)$. It was confirmed that N-BPs inhibit proliferation, decrease viability and induce apoptosis in various tumor cells. However, few studies have examined OPG and RANKL levels in the MG-63 osteosarcoma cell line as well as the effects of N-BPs on these cytokines. Zoledronic acid (ZOL) is a nitrogen-containing third generation bisphosphonate (N-BP). In the present study, we examined the effects of ZOL on MG-63 cells. We also assessed the expression of RANKL and OPG in MG-63 cells treated with or without ZOL. 


\section{Materials and methods}

Drug preparation. The neutralized sodium salt of ZOL (Novartis, Basel, Switzerland) was dissolved in sterile double distilled $\mathrm{H}_{2} \mathrm{O}$ at a final concentration of $10 \mathrm{mM}$. The stock solution of the ZOL salt was aliquoted and maintained at $-20^{\circ} \mathrm{C}$ for long-term storage.

Cell lines and culture maintenance. MG-63 human osteosarcoma cells were cultured in Eagle's minimum essential medium (EMEM) with $2 \mathrm{mM} \mathrm{L-glutamine} \mathrm{and} \mathrm{Earle's} \mathrm{BSS}$ adjusted to contain $1.5 \mathrm{~g} / 1$ sodium bicarbonate, $0.1 \mathrm{mM}$ non-essential amino acids, $1.0 \mathrm{mM}$ sodium pyruvate and $10 \%$ heat-inactivated fetal bovine serum in a humidified atmosphere of $5 \% \mathrm{CO}_{2}$ at $37^{\circ} \mathrm{C}$.

Cell growth and viability assays. Cells $\left(100 \mu 1,2 \times 10^{4}\right.$ cells/ $\mathrm{ml})$ were plated in each well in 96-well plates and allowed to attach for $24 \mathrm{~h}$. Cells were then treated with $0,0.3,1,3$, $10,30,100,300$ and $1000 \mu \mathrm{M}$ of ZOL for 24,48 and $72 \mathrm{~h}$. The proportion of viable cells was determined by MTT assay following the manufacturer's instructions. In brief, the cells were incubated with MTT $(0.5 \mathrm{~g} / \mathrm{l})$ for $4 \mathrm{~h}$. The formazan precipitate was dissolved in $200 \mu 1 \mathrm{DMSO}$ and the absorbance at $550 \mathrm{~nm}$ was measured with a Benchmark microplate reader. The tumor inhibitory rate was calculated as (1 - OD experimental group/OD control group) x $100 \%$. Experiments were performed in triplicate.

Analysis of apoptosis and cell cycle arrest. Apoptosis induced by ZOL was quantified using the Annexin V-FITC Apoptosis Detection kit I (BD Biosciences, Franklin Lakes, NJ, USA). MG-63 cells were treated with $50 \mu \mathrm{M}$ of ZOL for 24,48 and $72 \mathrm{~h}$ and then washed twice with cold PBS and re-suspended in $1 \mathrm{X}$ binding buffer at a concentration of $1 \times 10^{6} \mathrm{cells} / \mathrm{ml}$. The solution $\left(100 \mu 1,1 \times 10^{5}\right.$ cells) was transfered to a 5 -ml culture tube and $5 \mu 1$ Annexin V-FITC and $5 \mu 1$ propidium iodide (PI) were added. The cells were gently vortexed and incubated for $15 \mathrm{~min}$ at room temperature $\left(25^{\circ} \mathrm{C}\right)$ in the dark. $1 \mathrm{X}$ binding buffer $(400 \mu 1)$ was added to each tube. Samples were analyzed by flow cytometry within $1 \mathrm{~h}$. In the dual parameter fluorescent dot plots, the cells in early and late apoptosis were counted. Total cell apoptosis was defined as the sum of cells in early and late apoptosis. Experiments were performed in triplicate.

Confluent MG-63 cells (treated with increasing concentrations of ZOL for 24, 48 and $72 \mathrm{~h}$ ) were removed from culture dishes by trypsinization and fixed with ice-cold $70 \%$ ethanol at $-20^{\circ} \mathrm{C}$ overnight. Cells were washed with PBS, treated with DNase A (200 g/l, Sigma, St. Louis, MO, USA) and stained with PI (50 g/l, Sigma) at room temperature for $30 \mathrm{~min}$ in the dark. Cell cycle distribution was determined by the FACSCalibur flow cytometer (BD Biosciences).

Hoechst 33258 staining and electron microscopy. Cells were treated with $50 \mu \mathrm{M}$ of $\mathrm{ZOL}$ for $72 \mathrm{~h}$, harvested, cytospun onto glass slides and fixed with a $50 \%$ solution of fixative (3:1 methanol/acetic acid). The preparations were stained with Hoechst 33258 (10 mg/l Sigma) for $30 \mathrm{~min}$, rinsed, dried and visualized under a fluorescence microscope (Nikon, Japan). Confluent MG-63 cells were treated with $50 \mu \mathrm{M}$ of ZOL for

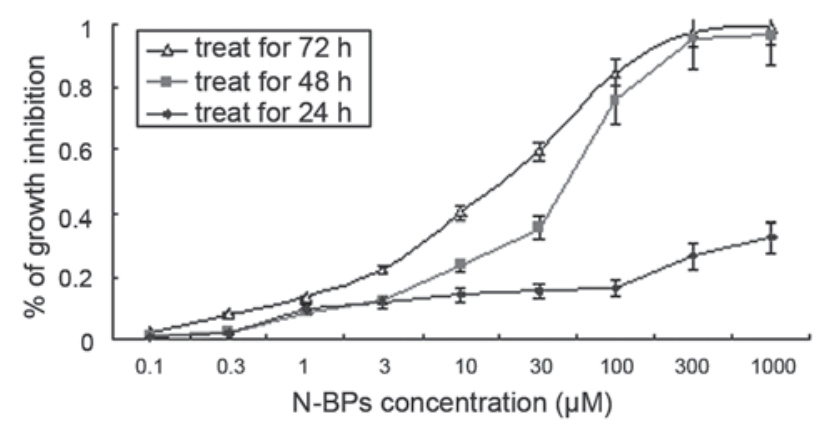

Figure 1. Effect of zoledronic acid on proliferation of MG-63 cells. Cells were incubated at a concentration of 0 (control), 0.3, 1, 3, 10, 30, 100, 300 and $1000 \mu \mathrm{M}$ of N-BP for 24, 48 and $72 \mathrm{~h}$ exposure and cell proliferation was determined by MTT assay. The mean value was calculated from three independent experiments. The bar is the standard deviation (SD). N-BPs, nitrogen-containing bisphosphonates.

$72 \mathrm{~h}$. Cells were trypsinized, centrifuged, fixed in $2.5 \%$ glutaraldehyde, postfixed in $2 \%$ osmium tetroxide and embedded in Luveak-812 (Nacalai Tesque, Japan). Ultrathin sections were stained with lead citrate and uranyl acetate and examined with a JEM-1230 electron microscope (Jeol Tokyo, Japan).

Reverse-transcription polymerase chain reaction (RT-PCR). Total cellular RNA was isolated using the RNAgents Total RNA Isolation system (Promega, Madison, WI, USA). The cDNA was synthesized using a reverse-transcription system (Promega). RT-PCR was performed using Takara Ex Taq Hot Start Version (Takara Bio, Shiga, Japan) and amplified by PCR using the specific primers (Sangon, Shanghai, China): 5'-TGCT GTTCCTACAAAGTTTACG-3' (sense) and 5'-CTTTGATGC TTTAGTGCGTG-3' (antisense) for OPG; 5'-GCCAGTGGG AGATGTTAG-3' (sense) and 5'-TTAGCTGCAAGTTTT CCC-3' (antisence) for RANKL; 5'-ACCCACACGGTGCCC ATCTACGAGG-3' (sense) and 5'-AGCTCGTAGCTCTTCT CCAGGGAGG-3' (antisense) for $\beta$-actin. Following denaturation at $95^{\circ} \mathrm{C}$ for $3 \mathrm{~min}$, samples were amplified for 30 cycles for OPG $\left(95^{\circ} \mathrm{C}, 1 \mathrm{~min} ; 57^{\circ} \mathrm{C}, 1 \mathrm{~min} ; 72^{\circ} \mathrm{C}, 1 \mathrm{~min}\right)$ and RANKL $\left(95^{\circ} \mathrm{C}, 1 \mathrm{~min} ; 55^{\circ} \mathrm{C}, 1 \mathrm{~min} ; 72^{\circ} \mathrm{C}, 1 \mathrm{~min}\right)$ and 30 cycles for $\beta$-actin $\left(95^{\circ} \mathrm{C}, 1 \mathrm{~min} ; 54^{\circ} \mathrm{C}, 1 \mathrm{~min} ; 72^{\circ} \mathrm{C}, 1 \mathrm{~min}\right)$. The PCR products were subjected to electrophoresis on $1.5 \%$ agarose gel with ethidium bromide and observed under UV light.

Western blot analysis. MG-63 cells $\left(5 \times 10^{5}\right)$ were plated and treated with $0,1,10,100 \mu \mathrm{M}$ of ZOL for $72 \mathrm{~h}$. Cells were then lysed with a lysis buffer composed of $50 \mathrm{mmol} / \mathrm{l} \mathrm{Tris-HCl}$ (pH 8.0), $150 \mathrm{mmol} / \mathrm{l} \mathrm{NaCl}, 0.1 \%$ Triton X-100, $0.01 \mathrm{~g} / \mathrm{l}$ aprotinin and $0.05 \mathrm{~g} / 1$ phenylmethylsulfonyl fluoride. Protein was quantified by the Bradford method and equal amounts of protein were loaded and electrophoresed on a $10 \%$ sodium dodecyl sulfate-polyacrylamide gel electrophoresis minigel. Proteins were transferred to a PVDF membrane and preblocked with casein PBS and $0.05 \%$ Tween-20 for $1 \mathrm{~h}$ at room temperature. Membranes were incubated with mouse monoclonal antibody against OPG (Santa Cruz Biotechnology, Santa Cruz, CA, USA). Horseradish peroxidase-conjugated secondary antibody against anti-mouse monoclonal antibody was used and protein bands were visualized with enhanced chemiluminescence reagent (ECL kit, Amersham, UK). 


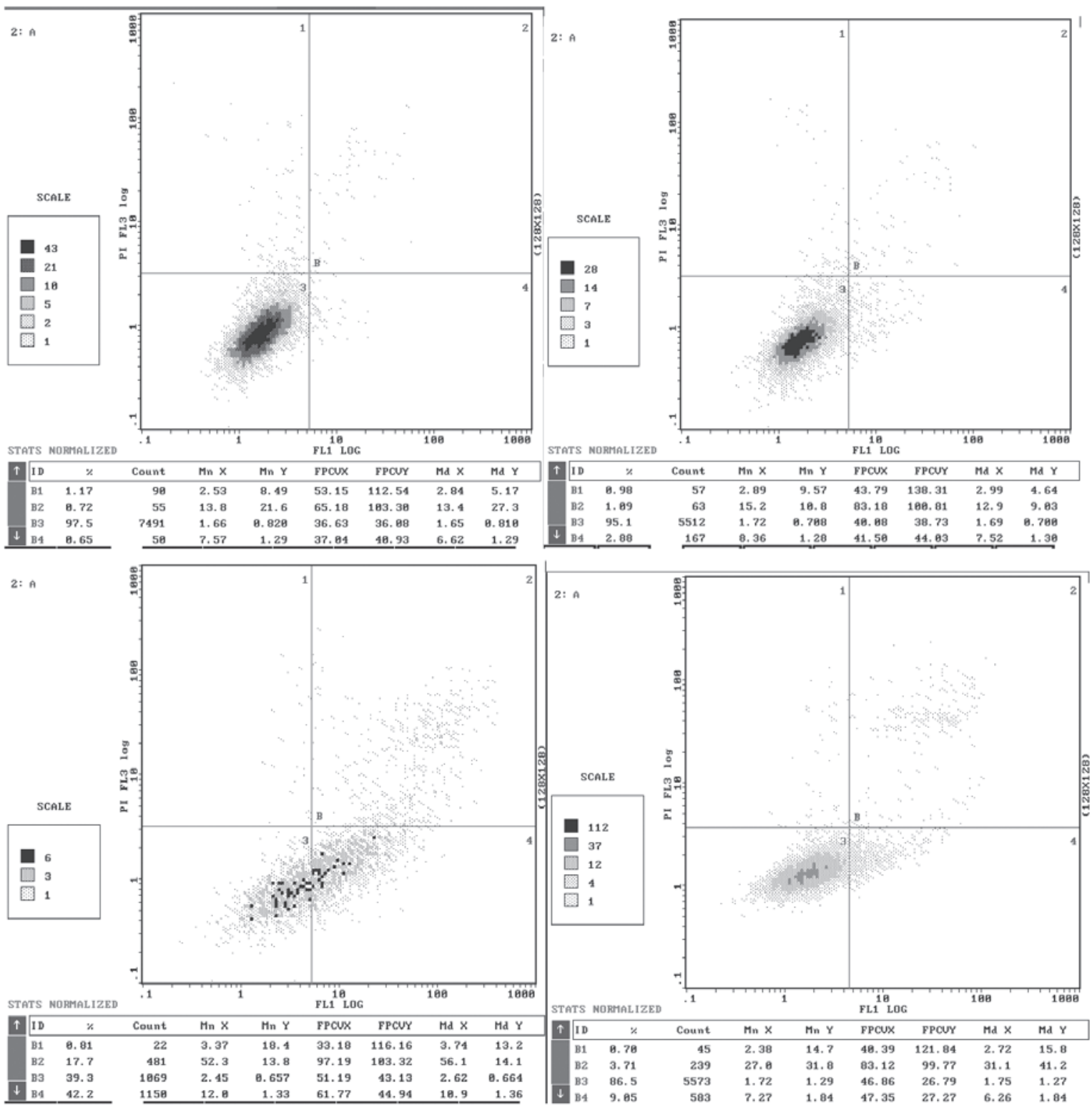

Figure 2. Cells were incubated with $50 \mu \mathrm{M}$ bisphosphonates for $72 \mathrm{~h}$. Apoptotic and dead cells were analyzed by flow cytometry using dual staining with propidium iodide (PI) and Annexin V-FITC. Bisphosphonates induced viable apoptotic cells stained with Annexin V alone (lower right quadrant) in MG-63, but only dead cells stained with PI (both upper left and right quadrants) were induced. After treatment for $72 \mathrm{~h}$, induced $42.2 \pm 2.1 \%$ apoptotic cells. Results shown are representative of three independent experiments.

Statistical analysis. Statistical significance was determined using the Student's t-test, using SPSS 13.0. $\mathrm{P}<0.05$ was considered to indicate a statistically significant result.

\section{Results}

Effect of ZOL on cell proliferation in MG-63 cells. To evaluate the growth inhibitory effect of N-BPs on the MG-63 cell line, we used the MTT assay and calculated the $\mathrm{IC}_{50}$ values. There was no significant $(P>0.001)$ growth inhibition in a dose-dependent manner following treatment with N-BPs for $24 \mathrm{~h}$. However, following treatment for $48 \mathrm{~h}$, ZOL significantly inhibited $(\mathrm{P}<0.001)$ MG-63 cell growth in a dose-dependent manner (Fig. 1). The calculated $\mathrm{IC}_{50}$ value for $\mathrm{ZOL}$ was $52.37 \pm 1.0 \mu \mathrm{M}$, following treatment with N-BPs for $72 \mathrm{~h}$. This concentration was used for subsequent experiments.
Induction of apoptosis. To determine the effects of $\mathrm{ZOL}$ on the induction of apoptosis in MG-63 cells, the Annexin $\mathrm{V}$ assay was performed. ZOL $(50 \mu \mathrm{M})$ treated for $72 \mathrm{~h}$ induced $42.2 \pm 2.1 \%$ apoptotic cells (Fig. 2). The preparations were stained with Hoechst 33258 and examined under a fluorescence microscope (Fig. 3). The blue emission light in apoptotic cells was much brighter than that observed in the control cells. Condensed chromatin was also observed in numerous treated cells and several of these cells formed apoptotic bodies, which is one of the classic characteristics of apoptotic cells. As shown by electron micrographs (Fig. 4), control cells demonstrated an integrated nuclear membrane, relatively homogeneous chromatin and extensive membrane interdigitations and microvilli. Following treatment with $50 \mu \mathrm{M}$ of $\mathrm{ZOL}$ for $72 \mathrm{~h}$, MG-63 cells were characterized by condensation into dense granules or blocks, migration 

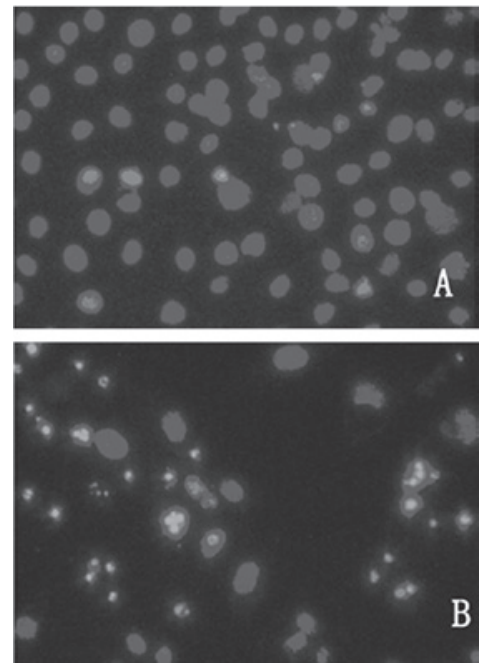

Figure 3. Fluorescence photomicrograph of MG-63 cells stained with Hoechst 33258. MG-63 cells were exposed to $50 \mu \mathrm{M}$ of zoledronic acid for $72 \mathrm{~h}$, harvested and cytospun onto glass slides for fixing. The preparations were stained with Hoechst 33258 and examined under fluorescence microscope. (A) Control; the nuclei were stained homogeneously and were less bright. (B) Treated cells; chromatin condensation occurred and apoptotic bodies formed. Magnification x200.

\section{A}

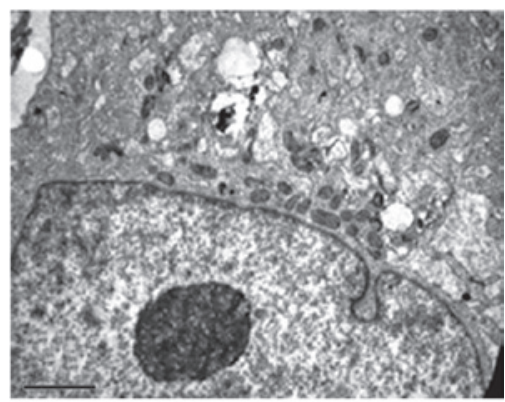

B

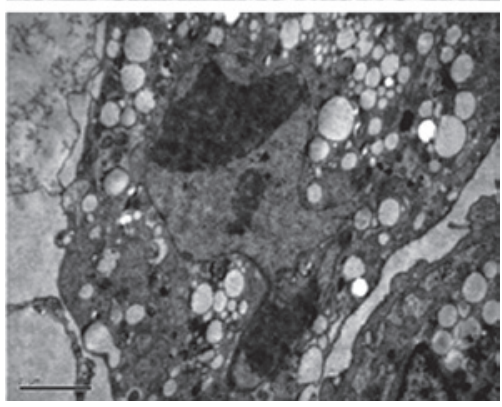

Figure 4. Electron micrographs of stained MG-63 cells. MG-63 cells were fixed in $2.5 \%$ glutaraldehyde, postfixed in $2 \%$ osmium tetroxide and embedded in Luveak-812. Ultrathin sections were stained with lead citrate and uranyl acetate and examined using a JEM-1230 electron microscope. Electron micrographs of (A) untreated cells and (B) cells treated with $50 \mu \mathrm{M}$ ZOL for $72 \mathrm{~h}$. (Scale bar, $10 \mu \mathrm{m}$ ).

of nuclear chromatin, formation of apoptotic bodies and numerous vacuoles in the cytoplasm. Concurrently, membrane microvilli also disappeared. These changes indicated the apoptosis of MG-63 cells.

ZOL induces $S$-phase arrest in MG-63 cells. To elucidate the molecular mechanism underlying the antitumor activity

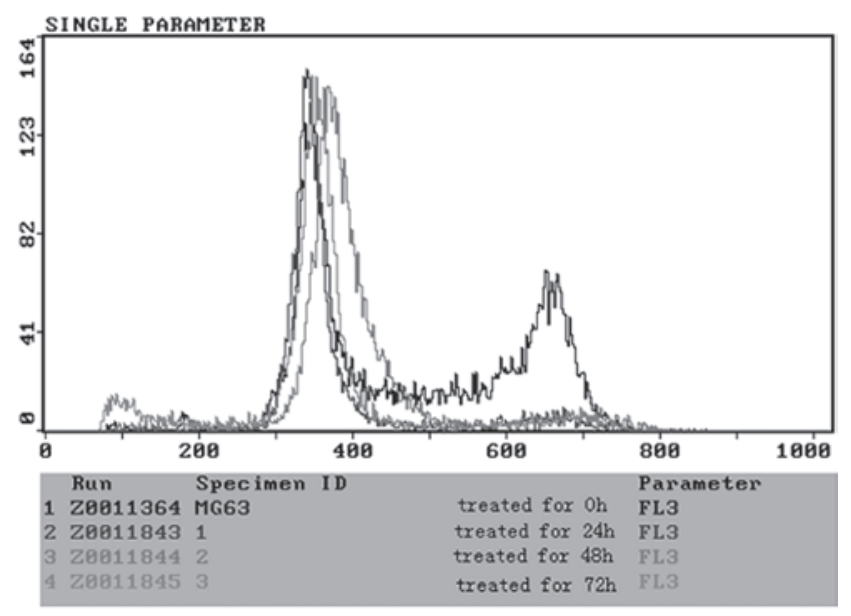

Figure 5. Flow cytometry of ZOL-treated MG-63 cells. MG-63 cells were incubated for 24,48 and $72 \mathrm{~h}$ in the absence (control) or presence of $50 \mu \mathrm{M}$ ZOL. At each point cells were harvested, fixed and stained with propidium iodide. The positions on the histograms of the hypodiploid sub- $\mathrm{G}_{0} / \mathrm{G}_{1}(\mathrm{APO})$, $\mathrm{G}_{0} / \mathrm{G}_{1}, \mathrm{~S}$ and $\mathrm{G}_{2} / \mathrm{M}$ peaks and the percentage of cells in each of the cycle phases are indicated from a representative experiment. ZOL, zoledronic acid.
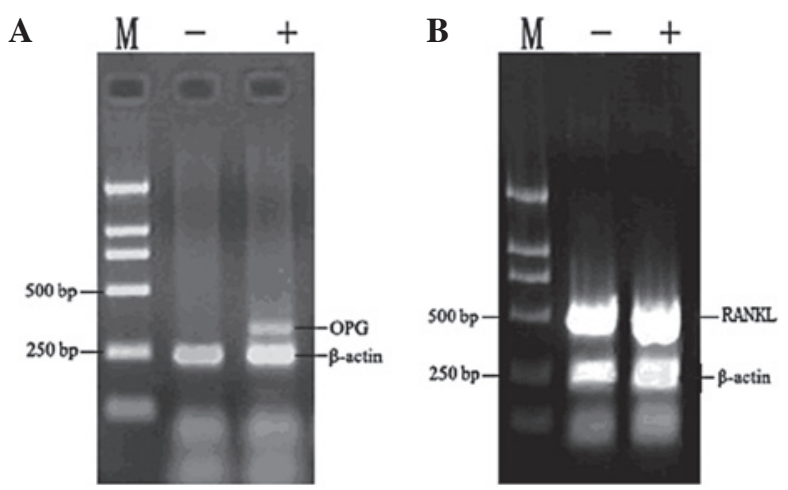

Figure 6. Effect of ZOL on (A) OPG and (B) RANKL mRNA expression in vitro. ZOL upregulated osteoprotegerin (OPG), but not RANKL expression in MG-63 cells. MG-63 cells were treated with $50 \mu \mathrm{M}$ ZOL for $72 \mathrm{~h}$. Total RNA was extracted and RT-PCR was performed using specific primers as described in Materials and methods. $18 \mathrm{~S}$ was used as the internal control. ZOL, zoledronic acid; RANKL, receptor activator of nuclear factor- $\mathrm{kB}$ ligand; RT-PCR, reverse-transcription polymerase chain reaction.

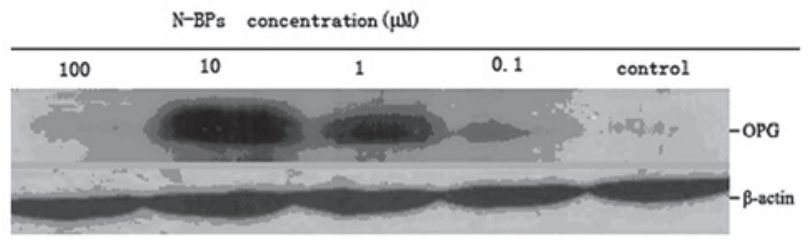

Figure 7. Concentration-course changes of OPG in MG-63 cells, treated with $0-100 \mu \mathrm{M} \mathrm{N}-\mathrm{BP}$ for $48 \mathrm{~h}$, using western blot analysis. Equal amounts of protein were loaded in each lane. $\beta$-actin was used as an internal control. Corresponding densitometric analysis of OPG and $\beta$-actin expression level is shown as the ratio of $\mathrm{OPG} / \beta$-actin. $\mathrm{OPG}$, osteoprotegerin; $\mathrm{N}-\mathrm{BP}$, nitrogencontaining bisphosphonates.

of N-BP, we examined the cell cycle distribution in MG-63 cells by flow cytometric analysis following PI staining. Significant changes were observed in the sub- $G_{1}, S$, and $G_{2} / M$ 
phase. Untreated control cells were found to have few or no cells in the apoptotic peak and a distribution of cells in the $\mathrm{G}_{0}-\mathrm{G}_{1}, \mathrm{~S}$ and $\mathrm{G}_{2} / \mathrm{M}$ phase typical of a proliferating cancer cell line. ZOL treatment induced an increase in the sub- $G_{1}$ peak in all cell lines, and an increase in the percentage of cells in the $\mathrm{G}_{1}$ phase was observed following treatment with $50 \mu \mathrm{M}$ ZOL in a time-dependent manner (Fig. 5). In view of the above-mentioned growth-inhibitory effects, experiments were performed to determine whether N-BP also induced apoptosis in the cell lines. A time-dependent increase in apoptosis was observed in cells treated with ZOL.

Effect of ZOL on osteoprotegerin expression in vitro. The RANK/RANKL/OPG pathway is important in the regulation of bone formation. Therefore, we aimed to determine whether ZOL has any impact on the expression of these genes. ZOL had no effect on the expression of RANKL in MG-63 cells (Fig. 6). By contrast, ZOL-treated cells demonstrated a significantly higher expression of OPG. $\beta$-actin was used as an internal loading control. Densitometric analysis revealed that ZOL induced 2.2-fold increases in OPG expression in MG-63 cells. There was no significant difference in the expression of either RANKL or RANK in the MG-63 cells.

Western blot analysis was performed to detect the OPG protein levels in cell culture media following treatment with ZOL in MG-63 cells. The OPG protein level increased following incubation with $0,1,10,100 \mu \mathrm{M}$ ZOL for $72 \mathrm{~h}$ (Fig. 7). The protein expression reached peak levels at $10 \mu \mathrm{M}$ and then decreased at $100 \mu \mathrm{M}$. ZOL stimulated osteoprotegerin protein production in the MG-63 cells.

\section{Discussion}

A number of studies have demonstrated the inhibitory potential of bisphosphonates on bone metastases from different solid tumors, including breast, prostate and pancreatic cancer and murine osteosarcoma $(5,6,7,15)$. In this study, we demonstrated that ZOL significantly inhibited human osteosarcoma growth and induced apoptosis in in vitro assays. Our data suggest that ZOL had direct effects on osteosarcoma cells, including the inhibition of tumor cell proliferation (Fig. 1) and induction of apoptosis (Fig. 2). These results are consistent with those of previous reports showing that N-BPs are able to inhibit cell proliferation and induce apoptosis in osteoclasts, myeloma, neuroblastoma and lung cancer cells $(4,13,16,17)$.

It has been suggested that N-BPs, including ZOL, are capable of inhibiting the activities of FPP synthase and geranylgeranyl diphosphate (GGPP) synthase, which are essential for the activation of FPP and GGPP. It should be noted that the activation of FPP and GGPP may result in the prenylation of small GTP-binding proteins including Ras and corresponding anti-apoptotic effects. Thus, it can be postulated that N-BPs induce cell apoptosis $(18,19)$. The results of the flow cytometric analysis confirmed that treatment of MG-63 with ZOL increased the $\mathrm{G}_{1}$ cell population (Fig. 5). From these findings, it is suggested that N-BPs exerted their anti-proliferative effect against MG-63 by the induction of cell apoptosis through the small GTP-binding proteins associated signal transduction pathway (20). Dunford et al demonstrated that YM529 showed direct antitumor effects on NSCLC cells, induced apoptosis and caused $\mathrm{G}_{1}$ arrest of the cell cycle through downregulation of the phosphorylation of ERK1/2 (18). Ory et al also confirmed that ZOL inhibited proliferation and increased atypical apoptosis in several osteosarcoma cell lines. However, these authors found that ZOL caused cell cycle arrest in the $S$ and $G_{2} / M$ phases, through the control of the intra-S DNA checkpoint at high doses of ZOL, or through the control of the $\mathrm{G}_{1} / \mathrm{S}$ DNA checkpoint at low doses (21).

In addition to apoptosis, N-BPs may regulate growth factors and cytokines that affect cancer cell progression. OPG and RANKL are able to affect the cancer phenotype. Bisphosphonates have been shown to increase OPG expression in osteoblast cells in in vitro assays. The increased OPG reduces osteolytic activity. Other studies have shown that bisphosphonates are capable of inhibiting FPP synthase in the mevalonate pathway, as well as the OPG pathway $(22,23)$. We observed that ZOL caused a downregulated expression of two pro-osteolytic molecules, consistent with previous reports. Our data indicate that ZOL upregulated the OPG expression (Figs. 6 and 7). This would in turn lead to a decrease in the RANKL/OPG ratio and decreased osteoclast activity (24). Ishii et al found that the sRANKL/OPG ratio decreased significantly following therapy in several myeloma patients. The ratio of serum RANKL/OPG correlated with the presence of osteolytic lesions and was a strong predictor of five-year survival (25). Mintz et al (26) defined a set of 104 genes that characterize poor histological response to chemotherapy in osteosarcoma. These authors found that a marked decrease of -5.44 of OPG suggested the involvement of osteoclast promotion in poorly responsive osteosarcoma tumors. They believed that the use of bisphosphonate analogs should be considered as a potential therapeutic intervention to suppress bone remodeling and tumor osteolysis involved in osteosarcoma chemotherapy resistance (26). In their study, Grimaud et al observed an increase in the RANKL/OPG ratio in the serum of patients with high-grade osteosarcoma (27). All of these findings suggest the potential involvement of the RANK/RANKL/OPG axis in osteosarcoma (28). OPG would decrease tumor burden and select plasma parameters of tumor burden and bone resorption by inhibiting osteoclastic bone resorption and tumor growth in an intratibial injection model of bone metastasis of a human pulmonary squamous cell carcinoma (29).

Previous studies have shown that N-BPs exert antitumor properties and interact synergistically with other antineoplastic agents (30). As bisphosphonates accumulate in bone, they exert cytostatic effects on tumor cells in bone metastases, either via osteoclast inhibition or alterations in the bone microenvironment. Further in vivo studies are required to optimize the dosing regimen of N-BPs to fully exploit their antitumor potential. However, the present experiments do not completely rule out that OPG inhibits tumor growth specifically in the bone microenvironment. Further experiments are needed to determine the true effects of OPG on osteosarcoma.

In conclusion, our results demonstrate that $\mathrm{ZOL}$ is able to directedly inhibit cell growth and induce apoptosis of MG-63 cells. Increased expression of osteoprotegerin was also observed, which may be an indirect effect via an alteration in the local microenvironment. 


\section{References}

1. Bacci G, Longhi A, Fagioli F, Briccoli A, Versari M and Picci P: Adjuvant and neoadjuvant chemotherapy for osteosarcoma of the extremities: 27 year experience at Rizzoli Institute, Italy. Eur J Cancer 41: 2836-2845, 2005.

2. Perry CM and Figgitt DP: Zoledronic acid: a review of its use in patients with advanced cancer. Drugs 64: 1197-1211, 2004.

3. Green JR: Skeletal complications of prostate cancer: pathophysiology and therapeutic potential of bisphosphonates. Acta Oncol 44: 282-292, 2005.

4. Baulch-Brown C, Molloy TJ, Yeh SL, Ma D and Spencer A: Inhibitors of the mevalonate pathway as potential therapeutic agents in multiple myeloma. Leuk Res 31: 341-352, 2007.

5. Iguchi K, Nakano T, Usui S and Hirano K: Incadronate inhibits aminopeptidase $\mathrm{N}$ expression in prostatic PC-3 cells. Cancer Lett 237: 223-233, 2006.

6. Nakajima H, Magae J, Tsuruga M, Sakaguchi K, Fujiwara I, Mizuta M, Sawai K, Yamagishi H and Mizuta N: Induction of mitochondria-dependent apoptosis through the inhibition of mevalonate pathway in human breast cancer cells by YM529, a new third generation bisphosphonate. Cancer Lett 253: 89-96, 2007.

7. Tassone P, Tagliaferri P, Viscomi C, Palmieri C, Caraglia M, D'Alessandro A, Galea E, Goel A, Abbruzzese A, Boland CR and Venuta S: Zoledronic acid induces antiproliferative and apoptotic effects in human pancreatic cancer cells in vitro. Br J Cancer 88: 1971-1978, 2003.

8. Im GI, Qureshi SA, Kenney J, Rubash HE and Shanbhag AS: Osteoblast proliferation and maturation by bisphosphonates Biomaterials 25: 4105-4115, 2004.

9. Viereck V, Emons G, Lauck V, Frosch KH, Blaschke S, Gründker C and Hofbauer LC: Bisphosphonates pamidronate and zoledronic acid stimulate osteoprotegerin production by primary human osteoblasts. Biochem Biophys Res Commun 291: 680-686, 2002.

10. Wittrant Y, Théoleyre S, Chipoy C, Padrines M, Blanchard F, Heymann D and Rédini F: RANKL/RANK/OPG: new therapeutic targets in bone tumours and associated osteolysis. Biochim Biophys Acta 1704: 49-57, 2004.

11. Dougall WC and Chaisson M: The RANK/RANKL/OPG triad in cancer-induced bone diseases. Cancer Metastasis Rev 25: 541-549, 2006

12. Baud'huin M, Duplomb L, Ruiz Velasco C, Fortun Y, Heymann D and Padrines M: Key roles of the OPG-RANK-RANKL system in bone oncology. Expert Rev Anticancer Ther 7: 221-232, 2007.

13. Plotkin LI, Manolagas SC and Bellido T: Dissociation of the pro-apoptotic effects of bisphosphonates on osteoclasts from their anti-apoptotic effects on osteoblasts/osteocytes with novel analogs. Bone 39: 443-452, 2006.

14. Green JR: Antitumor effects of bisphosphonates. Cancer 97: 840-847, 2003.

15. Horie N, Murata H, Nishigaki Y, Matsui T, Segawa H, Nogawa M, Yuasa T, Kimura S, Maekawa T, Fushiki S and Kubo T: The third-generation bisphosphonates inhibit proliferation of murine osteosarcoma cells with induction of apoptosis. Cancer Lett 238 : 111-118, 2006

16. Koshimune R, Aoe M, Toyooka S, Hara F, Ouchida M, Tokumo M, Sano Y, Date H and Shimizu N: Anti-tumor effect of bisphosphonate (YM529) on non-small cell lung cancer cell lines. BMC Cancer 7: 8, 2007.

17. Dickson PV, Hamner JB, Cauthen LA, Ng CY, McCarville MB and Davidoff AM: Efficacy of zoledronate against neuroblastoma. Surgery 140: 227-235, 2006.
18. Dunford JE, Thompson K, Coxon FP, Luckman SP, Hahn FM, Poulter CD, Ebetino FH and Rogers MJ: Structure-activity relationships for inhibition of farnesyl diphosphate synthase in vitro and inhibition of bone resorption in vivo by nitrogencontaining bisphosphonates. J Pharmacol Exp Ther 296: 235-242, 2001

19. Ishikawa C, Matsuda T, Okudaira T, Tomita M, Kawakami H, Tanaka Y, Masuda M, Ohshiro K, Ohta T and Mori N: Bisphosphonate incadronate inhibits growth of human T-cell leukaemia virus type I-infected T-cell lines and primary adult T-cell leukaemia cells by interfering with the mevalonate pathway. Br J Haematol 136: 424-432, 2007.

20. Caraglia M, Santini D, Marra M, Vincenzi B, Tonini G and Budillon A: Emerging anti-cancer molecular mechanisms of aminobisphosphonates. Endocr Relat Cancer 13: 7-26, 2006.

21. Ory B, Blanchard F, Battaglia S, Gouin F, Rédini F and Heymann D: Zoledronic acid activates the DNA S-phase checkpoint and induces osteosarcoma cell death characterized by apoptosis-inducing factor and endonuclease-G translocation independently of p53 and retinoblastoma status. Mol Pharmacol 71: 333-343, 2007.

22. Mori K, Le Goff B, Berreur M, Riet A, Moreau A, Blanchard F, Chevalier C, Guisle-Marsollier I, Léger J, Guicheux J, et al: Human osteosarcoma cells express functional receptor activator of nuclear factor-kappa B. J Pathol 211: 555-562, 2007

23. Benassi MS, Chiechi A, Ponticelli F, Pazzaglia L, Gamberi G, Zanella L, Manara MC, Perego P, Ferrari S and Picci P: Growth inhibition and sensitization to cisplatin by zoledronic acid in osteosarcoma cells. Cancer Lett 250: 194-205, 2007.

24. Zhang J, Dai J, Qi Y, Lin DL, Smith P, Strayhorn C, Mizokami A, Fu Z, Westman J and Keller ET: Osteoprotegerin inhibits prostate cancer-induced osteoclastogenesis and prevents prostate tumor growth in the bone. J Clin Invest 107: 1235-1244, 2001.

25. Ishii R, Morimoto A, Ikushima S, Sugimoto T, Asami K, Bessho F, Kudo K, Tsunematu Y, Fujimoto J and Imashuku S: High serum values of soluble CD154, IL-2 receptor, RANKL and osteoprotegerin in Langerhans cell histiocytosis. Pediatr Blood Cancer 47: 194-199, 2006

26. Mintz MB, Sowers R, Brown KM, Hilmer SC, Mazza B, Huvos AG, Meyers PA, Lafleur B, McDonough WS, Henry MM, et al: An expression signature classifies chemotherapy-resistant pediatric osteosarcoma. Cancer Res 65: 1748-1754, 2005.

27. Grimaud E, Soubigou L, Couillaud S, Coipeau P, Moreau A, Passuti N, Gouin F, Redini F and Heymann D: Receptor activator of nuclear factor kappaB ligand (RANKL)/osteoprotegerin (OPG) ratio is increased in severe osteolysis. Am J Pathol 163: 2021-2031, 2003.

28. Quinn JE, Brown LG, Zhang J, Keller ET, Vessella RL and Corey E: Comparison of Fc-osteoprotegerin and zoledronic acid activities suggests that zoledronic acid inhibits prostate cancer in bone by indirect mechanisms. Prostate Cancer Prostatic Dis 8: 253-259, 2005.

29. Tannehill-Gregg SH, Levine AL, Nadella MV, Iguchi H and Rosol TJ: The effect of zoledronic acid and osteoprotegerin on growth of human lung cancer in the tibias of nude mice. Clin Exp Metastasis 23: 19-31, 2006.

30. Zheng Y, Zhou H, Brennan K, Blair JM, Modzelewski JR, Seibel MJ and Dunstan CR: Inhibition of bone resorption, rather than direct cytotoxicity, mediates the anti-tumour actions of ibandronate and osteoprotegerin in a murine model of breast cancer bone metastasis. Bone 40: 471-478, 2007. 